\title{
Long-Term Acting and Orally Active Vanadyl-Methylpicolinate Complex with Hypoglycemic Activity in Streptozotocin-Induced Diabetic Rats
}

\author{
Seiki Fujmoto, ${ }^{1}$ Kumiko FujII, ${ }^{1}$ Hiroyuki Yasui, ${ }^{1}$ Rokuji Matsushita, ${ }^{2}$ \\ Jitsuya TAKADA, ${ }^{2}$ and Hiromu SAKURAI ${ }^{1, *}$ \\ ${ }^{1}$ Department of Analytical and Bioinorganic Chemistry, Kyoto Pharmaceutical University, \\ Yamashina-ku, Kyoto 607, Japan \\ ${ }^{2}$ Research Reactor Institute, Kyoto University, Kumatori-cho, \\ Osaka 590-04, Japan
}

(Received May 12, 1997)

Summary The therapy of insulin-dependent diabetes mellitus (IDDM) is achieved only by daily subcutaneous injections of insulin, and compounds that can replace insulin or insulin-mimetics for oral administration need to be developed. Vanadate ion, vanadyl ion and their complexes have been reported to possess insulin-mimetic activities in both in vitro and in vivo experiments. On the basis of our recent preliminary finding that a bis(picolinato)oxovanadium (VO-PA) complex has a possible hypoglycemic activity when given by oral administration to streptozotocin-induced diabetic rats (STZ-rats), we synthesized several analogs of the VO-PA complex and examined the relationship between their structures and insulin-mimetic activity. Bis(methylpicolinato)oxovanadium (VO-MPA) complex, which has a relatively high partition coefficient among the prepared complexes, was found to be effective to inhibit in vitro release of free fatty acid from isolated rat adipocytes, similar to VO-PA. VO-MPA complex was thus given to STZ-rats by intraperitoneal injection or oral administration, and was found to normalize the serum glucose levels without the body weight loss. Especially, on oral administration of the complex, the normal serum glucose level was maintained for 80 days after the cessation of the complex administration. The long-acting character of the complex was suggested by the fact that vanadium is incorporated in bone as well as in kidney or other organs. Based on these observations, VO-MPA was proposed to be an useful agent not only to treat IDDM in experimental animals but to analyze the mechanism for the insulin mimetic activity of vanadium compounds.

\footnotetext{
*To whom correspondence should be addressed.
} 
Key Words: vanadyl complex, diabetes, oral administration, vanadylmethylpicolinate, organ distribution

Vanadium has been proposed and accepted to be an essential trace element in animals such as rats and chickens [1-3], however, there is yet no demonstration of its essentiality in humans. Since the vanadate ion $(+5$ oxidation state of vanadium) was found to be a potent inhibitor of $\mathrm{Na}^{+}, \mathrm{K}^{+}$-ATPase in 1977 [4], the biological actions of vanadium on such organs as heart [5-7], smooth muscle [5, 8], kidney [5], stomach [9], eye [5, 10], ear [5], brain [5], and pancreas [5, 1113] have been investigated by many researchers. Among them, the insulin-like effect of vanadium is the most remarkable finding, and the relationship between vanadium and diabetes mellitus has extensively been studied $[6,9,14-18]$. Recently, the insulin-like effect of sodium metavanadate $[19,20]$, vanadyl sulfate [21-22], and its complexes [23-26] by oral administration has been demonstrated in the streptozotocin-induced diabetic rats (STZ-rats). The mechanism for the action of vanadium has been proposed from the results showing stimulation of glycogen synthesis, glucose uptake into the adipocytes [27, 28] and free fatty acid (FFA) release from adipocytes [27]. The actions of vanadium on enzyme systems such as adenylate cyclase [29], glycogen phosphorylase [7], phosphorylase kinase [7], tyrosine kinase [30-32], phosphotyrosine phosphatase [32], phospholipase $\mathrm{A}_{2}$ [33], ketohexokinase [10], aldolase [10], calcium transport system through calmodulin [34] and insulin receptor in the place of insulin [11-13,35] were also reported.

All types of diabetes mellitus involve absolute or relative insulin deficiency. Among them, the therapy of insulin-dependent diabetes mellitus (IDDM), which involves many serious secondary complications such as diabetic retinopathy, diabetic nephropathy, and diabetic neuropathy, requires the daily subcutaneous (s.c.) injection of insulin. To avoid the pain and stress due to the s.c. injection of insulin to the patients, the development of orally active insulin replacements or mimetics is an essentially important investigation. We are studying the development of orally active vanadium complex to treat IDDM. Recently, we have proposed that bis(picolinato)oxovanadium (VO-PA) complex is effective by oral administration to treat the diabetes of STZ-rats [26] after the fundamental investigations on vanadyl complexes with various coordination modes such as $\mathrm{VO}\left(\mathrm{O}_{4}\right)$ [23], $\operatorname{VO}\left(\mathrm{S}_{2} \mathrm{~N}_{2}\right)$ [23] and $\operatorname{VO}\left(\mathrm{S}_{4}\right)$ [25]. The results indicated that the VO-PA complex with $\operatorname{VO}\left(\mathrm{N}_{2} \mathrm{O}_{2}\right)$ coordination mode was useful for developing new vanadyl complexes as a leading compound with hypoglycemic activity. In this study, we prepared several analogs (Fig. 1) of the VO-PA complex and examined the relationship between their structures and insulin-mimetic activity by evaluating both in vitro and in vivo experimental results. We report here the results on the ability of a group of vanadyl complex to mimic insulin action in vitro and in vivo, and propose that bis(methylpicolinato)oxovanadium (VO-MPA) is more active 


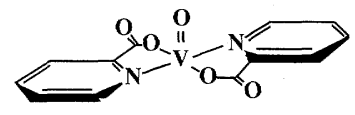

Bis(picolinato)oxovanadium

(VO-PA)

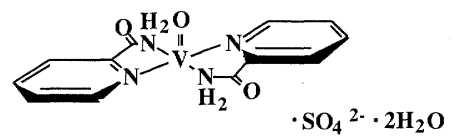

Bis(picolinamide)oxovanadium (VO-PAM)

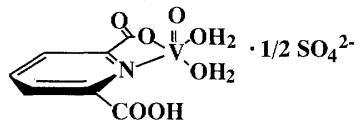

(Dipicolinato)oxovanadium (VO-DPA)

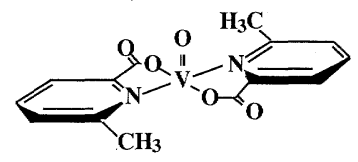

Bis(methylpicolinato)oxovanadium (VO-MPA)

Fig. 1. Structures of vanadyl complexes.

and less toxic by oral administration to STZ-rats than VO-PA.

\section{MATERIALS AND METHODS}

Materials. Vanadyl sulfate $\left(\mathrm{VOSO}_{4} \cdot 4 \mathrm{H}_{2} \mathrm{O}\right)$, picolinic acid (PA), 2,6-dipicolinic acid (DPA), D(+)-glucose, collagenase, and acacia were purchased from Wako Pure Chemicals, Osaka. 2-Picolinamide (PAM) and 6-methylpicolinic acid (MPA) were obtained from Tokyo Kasei Organic Chemicals, Tokyo. Streptozotocin (STZ), ( \pm )-epinephrine hydrochloride, and bovine serum albumin (BSA; fraction V) were from Sigma Chemical Co., St. Louis, MO. Purity of $\mathrm{VOSO}_{4} \cdot 4 \mathrm{H}_{2} \mathrm{O}$ was determined by chelatometry using EDTA-Na $\mathrm{Na}_{2}$ and $\mathrm{Cu}-\mathrm{PAN}$ (Cu-1-(2-pyridylazo)-2-naphthol complex, Dojindo, Kumamoto).

Preparation of vanadyl complexes and their physico-chemical characterizations. Bis(picolinato)oxovanadium (IV) (VO-PA), bis(picolinamide)oxovanadium (IV) (VO-PAM), and bis(methylpicolinato)oxovanadium (IV) (VO-MPA) (Fig. 1) were prepared in aqueous solution at $\mathrm{pH} 6.0-7.0$ by mixing ligand $(1.0 \mathrm{M})$ and vanadyl sulfate (VS) $(0.5 \mathrm{M})$ at a $2: 1$ molar ratio, and (dipicolinato)oxovanadium (IV) (VO-DPA) was prepared at a 1:1 molar ratio of DPA and VS. These complexes were characterized by their physico-chemical properties such as elemental analysis, visible (VIS) and infrared (IR) absorption spectra, electron spin resonance $(\mathrm{ESR})$ spectra measured at room $\left(25^{\circ} \mathrm{C}\right)$ and liquid nitrogen $(77 \mathrm{~K})$ temperature, magnetic susceptibility, and partition coefficient. VIS and IR spectra at room temperature were measured with a Shimadzu UV-1200 and a Shimadzu IR-408 with $\mathrm{KBr}$ disk, respectively. ESR spectra were recorded with a JEOL JES-REIX ESR spectrometer at a modulation frequency of $100 \mathrm{kHz}$, modulation amplitude of $0.63 \mathrm{mT}$, and microwave power of $5.0 \mathrm{~mW}$. The spectrometer was calibrated with an Advantest Microwave Counter, R5372. Magnetic susceptibil- 
ities were measured with a Sherwood Scientific MK-I at $25^{\circ} \mathrm{C}$. Magnetic moments, $\mu_{\text {eff }}$, were calculated from magnetic susceptibilities. The partition coefficients of the complexes were determined by a conventional method in a Krebs-Ringer bicarbonate (KRB) buffer ( $\mathrm{pH} 7.4) / n$-octanol system using an UV-VIS spectrometer (Shimadzu UV-1200). The concentrations of the complexes in each phase were monitored at their characteristic absorption bands due to the vanadyl state. The partition coefficient of the complexes was calculated by the following equation $P=C_{\text {oct }} / C_{\mathrm{w}}$, where $C_{\text {oct }}$ and $C_{\mathrm{w}}$, are the equilibrium concentrations of the complex in $n$-octanol and KRB buffer, pH 7.4, respectively, after shaking for $6 \mathrm{~h}$ at $37^{\circ} \mathrm{C}$.

Effect of vanadyl complexes on FFA release from isolated rat adipocytes. Isolated rat adipocytes were obtained by the method reported before [27]. Briefly, male Wistar rats, weighing $200 \mathrm{~g}$, were sacrificed by bleeding under anesthesia with ether, and the adipose tissue was removed. The adipose tissue was cut with scissors and digested with collagenase for $1 \mathrm{~h}$ at $37^{\circ} \mathrm{C}$ in $\mathrm{KRB}$ buffer, $\mathrm{pH} 7.4$, containing $2 \%$ BSA. Undigested tissues were removed by filtration (gauze Type I, Japanese Pharmacopeia, Tokyo). Adipocytes were washed three times with the same buffer. Isolated adipocytes $\left(240 \mu 1\right.$, about $3 \times 10^{6}$ cells $\left./ \mathrm{ml}\right)$ and $30 \mu 1$ of VS, VO-PA, VO-DPA, VO-PAM, or VO-MPA solution (final concentration, $1 \times 10^{-4}$ or $5 \times 10^{-4}$ M) dissolved in water or $2 \%$ dimethyl sulfoxide (DMSO) were mixed and preincubated for $30 \mathrm{~min}$ at $37^{\circ} \mathrm{C}$. Then $30 \mu 1$ of epinephrine (final concentration, $1 \times$ $10^{-5} \mathrm{M}$ ) was added, and the suspension was incubated for $3 \mathrm{~h}$ at $37^{\circ} \mathrm{C}$. The reaction was stopped by cooling with ice. FFA concentration in the supernatant was determined by a NEFA C-test WAKO kit (Wako Pure Chemicals). Due to the insolubility of the complexes in water or buffer solutions, we used 2\% DMSO solution of the complexes in the evaluation system, in which $2 \%$ DMSO solution was confirmed to have essentially no effects on the release of FFA from the adipocytes under the experimental conditions.

Preparation of STZ-rats. Diabetes was induced in male Wistar rats, weighing $200 \mathrm{~g}$, by a single intravenous (i.v.) injection of freshly prepared STZ (35 mg/ $\mathrm{kg}$ body weight) in $0.1 \mathrm{M}$ citrate buffer ( $\mathrm{pH} 5.0$ ) via a tail vein. Injections were performed under light ether anesthesia. STZ-rats with high serum glucose levels of 16-20 mM (or $300-350 \mathrm{mg} / \mathrm{dl}$ ) and low serum insulin levels of 22-33 pM one week after STZ administration were considered to be in diabetic state and were thus used for experiments.

Administration of vanadyl complexes to STZ-rats. STZ-rats received daily intraperitoneal (i.p.) injection ( 8 rats in each group) or oral administration ( 9 rats in a group) with a stainless sound $(0.9 \mathrm{~mm}$ i.d. and $1.0 \mathrm{~mm}$ o.d., $8 \mathrm{~cm}$ length) of VO-MPA at various doses at about 1 p.m. after the determination of their serum glucose levels. Blood samples $(6 \mu 1)$ for analysis of serum glucose level were obtained from a tail vein, and serum glucose levels were measured with a Fuji Dry-chem 100 or a Fuji Dry-chem Slide Glu-W (Fujifilm, Tokyo). Control and STZ-rats were allowed free access to solid food (MF, Oriental Yeast Co., Tokyo) and tap water. Body weights of control and STZ-rats were measured daily during 
the experiments. Intakes of solid food and drinking water in each rat were checked daily throughout the experiments. STZ-rats were given VO-MPA suspended in 5\% acacia at the doses of $3 \mathrm{mg}(58.8 \mu \mathrm{mol}) \mathrm{V}$ equivalent $/ \mathrm{kg}$ body weight for the first day, $2 \mathrm{mg}(39.2 \mu \mathrm{mol}) \mathrm{V} / \mathrm{kg}$ body weight for 2 days, and $1 \mathrm{mg}(19.6 \mu \mathrm{mol}) \mathrm{V} / \mathrm{kg}$ body weight for the following 11 days by i.p. injection, and then no administration of the complex for 14 days. Other STZ-rats were given the same complex suspended in $5 \%$ acacia at the doses of $10 \mathrm{mg}(196.0 \mu \mathrm{mol}) \mathrm{V} / \mathrm{kg}$ body weight for the first 10 days and $5 \mathrm{mg}(98.0 \mu \mathrm{mol}) \mathrm{V} / \mathrm{kg}$ body weight for the following 10 days by oral administration and then no administration of the complex for 80 days. Serum FFA, insulin, and blood urea nitrogen (BUN) levels were measured with an NEFA C-test Wako, a Glazyme insulin-EIA test, and a UN B-test Wako (Wako Pure Chemicals), respectively. Blood samples for measurements of these three parameters were obtained from a subclavian vein under light anesthesia with ether.

Oral glucose tolerance test. Once the blood glucose level of STZ-rats was reduced to a normal range by the complex administration, three animals received a glucose tolerance test. The serum glucose level of normal rats was between 5.6$8.3 \mathrm{mM}$ (or 100 to $150 \mathrm{mg} / \mathrm{dl}$ ). The rats were fasted for $12 \mathrm{~h}$, and glucose $(40 \%$ solution) at the dose of $3 \mathrm{~g} / \mathrm{kg}$ body weight was given orally. Blood samples $(6 \mu \mathrm{l})$ were obtained from a tail vein at $0.5,1,2,4$, and $6 \mathrm{~h}$ after glucose administration, and serum glucose levels were measured with a Fuji Dry-chem Slide Glu-W (Fujifilm).

Organ distribution of vanadium in STZ-rats given VO-MPA. Three STZrats were given a suspension of VO-MPA complex in 5\% acacia by i.p. injection at the dose of $3 \mathrm{mg}(58.8 \mu \mathrm{mol}) \mathrm{V} / \mathrm{kg}$ body weight for the first day, $2 \mathrm{mg}(39.2$ $\mu \mathrm{mol}) \mathrm{V} / \mathrm{kg}$ body weight for the following 2 days, and $1 \mathrm{mg}(19.6 \mu \mathrm{mol}) \mathrm{V} / \mathrm{kg}$ body weight for 11 days, and then given no treatment for 7 days. Once the serum glucose levels had fallen to the normal range, the rats were sacrificed under anesthesia with ether on the 21st day after the complex administration; and organs such as brain, lung, heart, liver, kidney, spleen, pancreas, adipose, bone, serum, and blood were removed and weighed. At autopsy, liver and kidney were pooled to obtain sufficient amounts of materials. Livers and kidneys were minced with scissors and homogenized. Homogenates were subsequently centrifuged and divided into four subcellular fractions, i.e., nuclear, mitochondrial, microsomal, and supernatant (cytosolic) by the usual procedure [36]. The organs and subcellular fractions were then lyophilized. Vanadium was determined by neutron activation analysis (NAA) method at the Research Reactor Institute of Kyoto University using the peak area of $1,434.1 \mathrm{keV}$ based on ${ }^{51} \mathrm{~V}(\mathrm{n}, \gamma){ }^{52} \mathrm{~V}$ reaction (half-life of ${ }^{52} \mathrm{~V}: 3.75 \mathrm{~min}$ ) [28]. Protein concentrations in the subcellular fractions were determined by the Lowry method [37].

In addition, organ and cellular distributions of vanadium in STZ-rats given oral VO-MPA complex suspended in $5 \%$ acacia at the dose of $10 \mathrm{mg}(196.0 \mu \mathrm{mol})$ $\mathrm{V} / \mathrm{kg}$ body weight for the first 10 days and then $5 \mathrm{mg}(98.0 \mu \mathrm{mol}) \mathrm{V} / \mathrm{kg}$ body weight for the following 10 days were also examined by NAA method. The 
animals were sacrificed on the 21 st day after the complex administration.

\section{RESULTS}

\section{Characterization of vanadyl complexes}

VO-PA complex and its analogs were characterized by several physicochemical methods as summarized in Table 1. For measurements of VIS absorption and ESR spectra, water was used as a solvent. In VIS absorption spectra of the four complexes, two absorption bands characteristic of the vanadyl state $\left(\mathrm{VO}^{2+}\right)$ were observed. In ESR spectra at both room and liquid nitrogen temperatures, an eight resonance line signal characteristic of the vanadyl state were detectable, and the ESR parameters such as $g$-values and hyperfine coupling constants ( $A$-values) were analyzed. In IR spectra, the band due to $\mathrm{V}=\mathrm{O}$ stretching frequency was found at $910-980 \mathrm{~cm}^{-1}$. The value of magnetic moments $\left(\mu_{\mathrm{eff}}=1.25-1.96\right)$ for the complexes supported that they were in a mononuclear vanadyl state. From these data together with the results of elemental analysis for the complexes, the structures of the complex were proposed as shown in Fig. 1. In VO-PA, VO-PAM, and VO-MPA complexes, the structure consisting of ligand : $\mathrm{VO}^{2+}=2: 1$ was suggested; whereas in the VO-DPA complex, the binding ratio of ligand : $\mathrm{VO}^{2+}$ at $1: 1$ was indicated. Among the four complexes, VO-MPA was found to have the highest partition coefficient.

Table 1. Physico-chemical properties of vanadyl complexes.

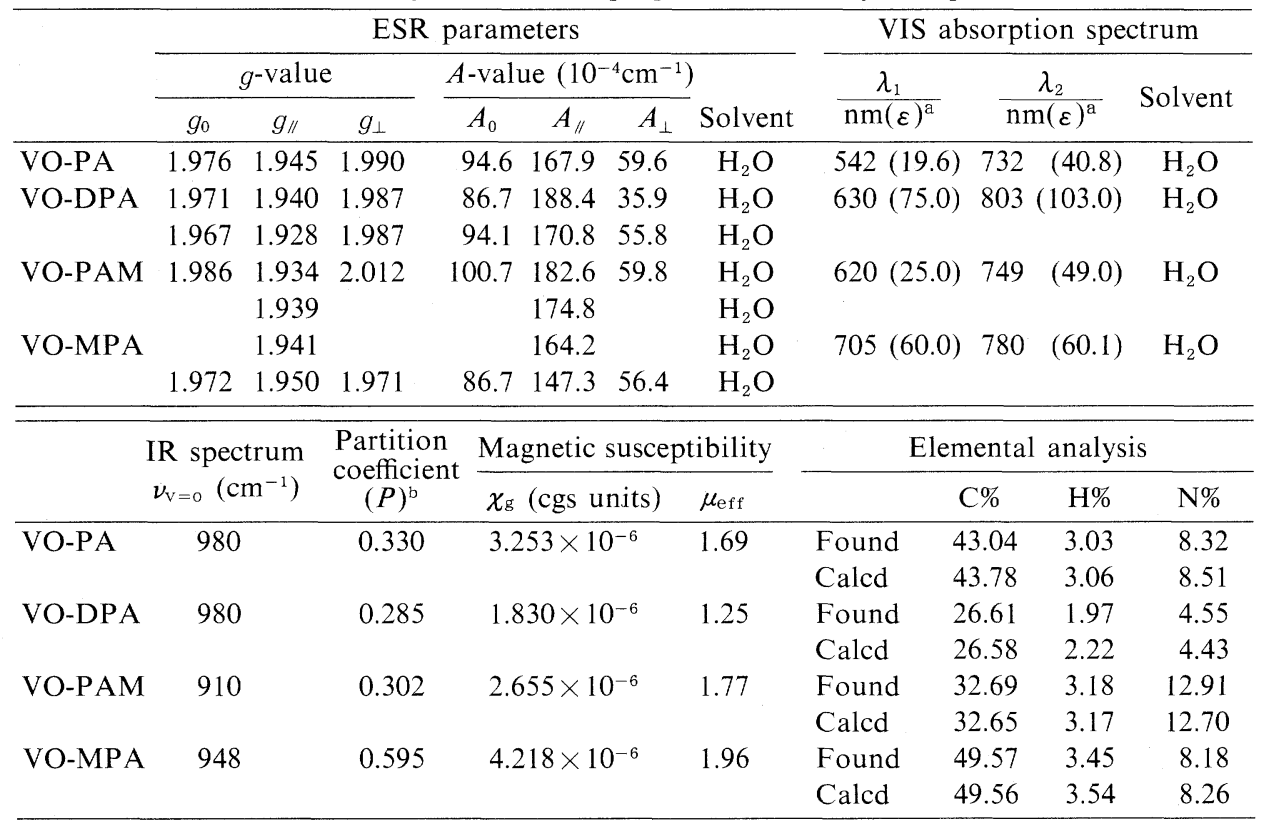

${ }^{\mathrm{a}} \mathrm{M}^{-1} \cdot \mathrm{cm}^{-1} \cdot{ }^{\mathrm{b}} n$-Octanol : buffer, $(\mathrm{pH} \mathrm{7.4)}=1: 1,6 \mathrm{~h}$. 
Effect of vanadyl complexes on FFA release from isolated rat adipocytes treated with epinephrine

To evaluate in vitro insulin mimetic activity of four vanadyl complexes, we examined the effect of these complexes on FFA release from isolated rat adipocytes treated with epinephrine in the absence of glucose as proposed before $[16,22,28$, $38,39]$. Figure 2 summarizes the effects of the four vanadyl complexes, comparing with that of VS as a positive control. Both VO-PA and VO-MPA complexes at $5 \times$ $10^{-4} \mathrm{M}$ inhibited FFA release from the epinephrine-stimulated adipocytes more than VS. Since these effects were found to be dose dependent in the concentration range of $10^{-4}-10^{-3} \mathrm{M}[26]$, the apparent $\mathrm{IC}_{50}$ values, $50 \%$ inhibition concentration of the FFA release in each system, were estimated. Apparent $\mathrm{IC}_{50}$ values of VO-PA and VO-MPA were estimated to be $4.7 \times 10^{-4} \mathrm{M}$ and $4.5 \times 10^{-4} \mathrm{M}$, respectively; whereas that of VS was $6 \times 10^{-3} \mathrm{M}$. Based on these results and the partition coefficient (Table 1) of the complexes, VO-MPA was selected for examination of its in vivo effect on STZ-rats.

\section{Serum glucose-normalizing effect of VO-MPA complexes on the STZ-rats}

First we examined the serum glucose-normalizing effect of VO-MPA complex on the STZ-rats. As shown in Fig. 3 (left), the serum glucose levels of STZ-rats dropped from hyperglycemic levels (approximately $27 \mathrm{mM}$ ) to the normal range (below $10 \mathrm{~mm}$ ) after one day of the treatment with VO-MPA given by i.p. injection, and the levels remained normal glucose levels during the administration for

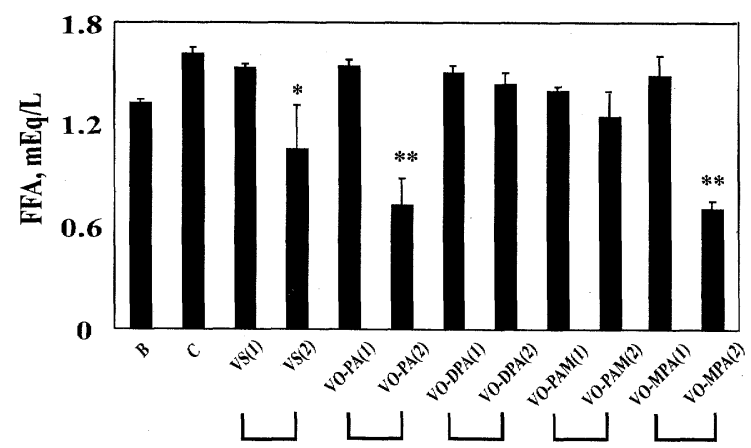

Fig. 2. Inhibitory effects of vanadyl sulfate (VS) and vanadyl complexes on FFA release from rat adipocytes treated with epinephrine in the absence of glucose. Data are expressed as the mean \pm SD for 3 experiments. B: blank, adipocytes were treated with saline for $30 \mathrm{~min}$ and then incubated for $3 \mathrm{~h}$ at $37^{\circ} \mathrm{C}$. C: control, adipocytes were treated with saline for $30 \mathrm{~min}$ and then incubated with $1 \times 10^{-5} \mathrm{M}$ epinephrine for $3 \mathrm{~h}$ at $37^{\circ} \mathrm{C}$. VS, VO-PA, VO-DPA, VO-PAM, and VO-MPA: adipocytes were treated with $1 \times 10^{-4}$ M (1) or $5 \times 10^{-4} \mathrm{M}$ (2) of VS, VO-PA, VO-DPA, VO-PAM, or VO-MPA, respectively, and then incubated with $1 \times 10^{-5} \mathrm{M}$ epinephrine for $3 \mathrm{~h}$ at $37^{\circ} \mathrm{C}$. Each column is expressed as the mean $\pm \mathrm{SD}$ for 3 experiments. Significance: ${ }^{*} p<0.05 ;{ }^{* *} p<0.01$., vs. control.

Vol. 23, No. 2, 1997 
2 weeks. After the cessation of the administration, their serum glucose levels were maintained at sub-normal values (approximately $8-15 \mathrm{~mm}$ ) for 10 days, but gradually increased thereafter. Body weights of the animals did not decrease but, rather, increased slightly for the first 8 days and then increased more gradually (Fig. 3, right). Serum glucose levels of the complex-treated STZ-rats returned to hyperglycemic levels (approximately $30 \mathrm{~mm}$ ) after 30 days, and the animals gained weight slightly. Based on these experimental results by i.p. administration, we speculated that the VO-MPA would be effective by oral administration, also.

Serum glucose levels of STZ-rats, which were given VO-MPA orally, were normalized at approximately $10 \mathrm{~mm}$ within 4 or 5 days after the start of treatment, and the levels remained normal during the remainder of the VO-MPA administration period (Fig. 4, upper). After the administration was stopped, the serum glucose level was still maintained at the normal level, around $10 \mathrm{~mm}$, for more than 80 days. Food consumption of STZ-rats was reduced during oral VO-MPA administration at the dose of $10 \mathrm{mg}(196.0 \mu \mathrm{mol}) \mathrm{V} / \mathrm{kg}$ body weight (Fig. 5). On the other hand, STZ-rats gained their body weights (Fig. 4, lower) after changing the dose to $5 \mathrm{mg}(98.0 \mu \mathrm{mol}) \mathrm{V} / \mathrm{kg}$ body weight, after which both food intakes and body weight increased gradually.

Serum parameters such as glucose, FFA, insulin, and BUN levels of STZ-rats given VO-MPA complex and those given VO-PA are summarized in Table 2. Since a positive correlation between serum glucose levels and serum FFA levels was found in normal and STZ-rats (unpublished data), we monitored these two parameters in the present study. When the serum glucose levels of STZ-rats were normalized by the treatment with VO-MPA, the serum FFA levels were also reduced. Serum insulin levels of STZ-rats were initially low, but they were slowly restored by VO-MPA treatment. STZ-rats treated with VO-PA or VO-MPA complex by i.p. injection exhibited high BUN levels. However, the difference in BUN levels of STZ-rats treated with VO-MPA complex was lower $(\Delta=3.0 \mathrm{~mm})$
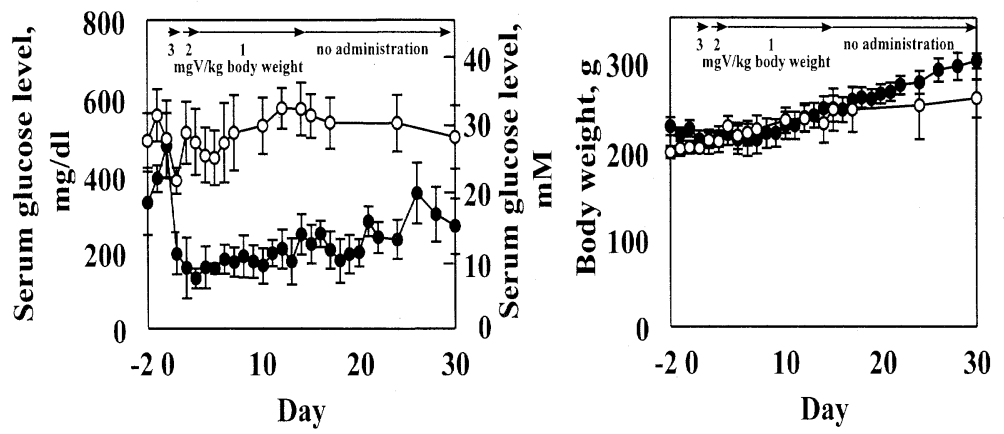

Fig. 3. Serum glucose and body weight changes in STZ-induced diabetic rats $(-\bigcirc-)$ and STZ-induced diabetic rats given VO-MPA complex by daily i.p. injections (- - ). Data are expressed as the mean $\pm \mathrm{SD}$ for 8 rats. 

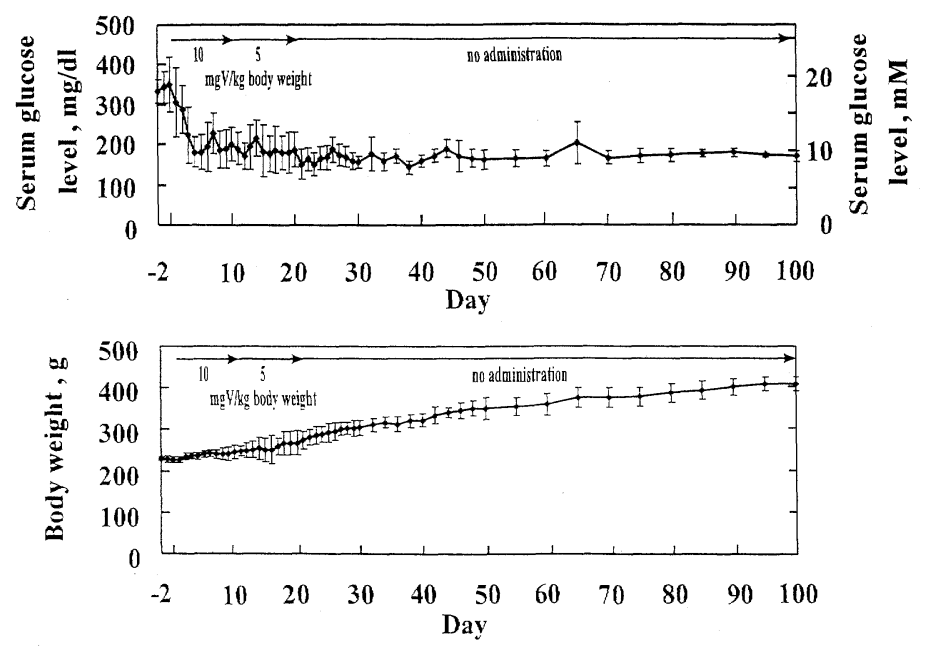

Fig. 4. Serum glucose and body weight changes in STZ-induced diabetic rats given VO-MPA complex by daily oral administration. Data are expressed as the mean $\pm \mathrm{SD}$ for 9 rats.

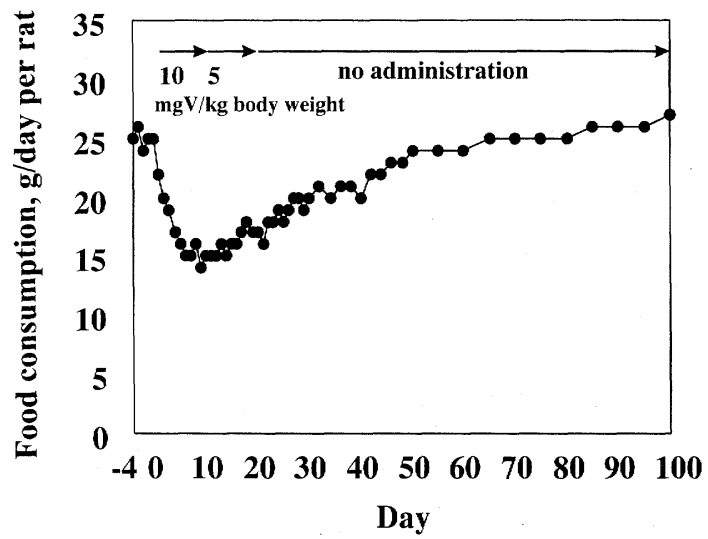

Fig. 5. Food intake of STZ-induced diabetic rats given VO-MPA complex by oral administration during the experimental period. Data were obtained from STZ-induced diabetic rats given VO-MPA complex by daily oral administration.

than that for the STZ-rats treated with VO-PA complex $(\Delta=21.3 \mathrm{~mm})$ after the 14 days of i.p. administration of the complexes. Whereas, remarkable changes in BUN levels after 14 or 20 days of the complex administration were not observed in STZ-rats treated by oral VO-PA or VO-MPA administration, respectively, the levels being in the range of $6.4-7.4 \mathrm{mM}$. When oral VO-PA administration was stopped, the BUN levels after 58 days were almost unchanged, compared with the initial BUN levels. While, in oral VO-MPA administration the BUN levels after 30 


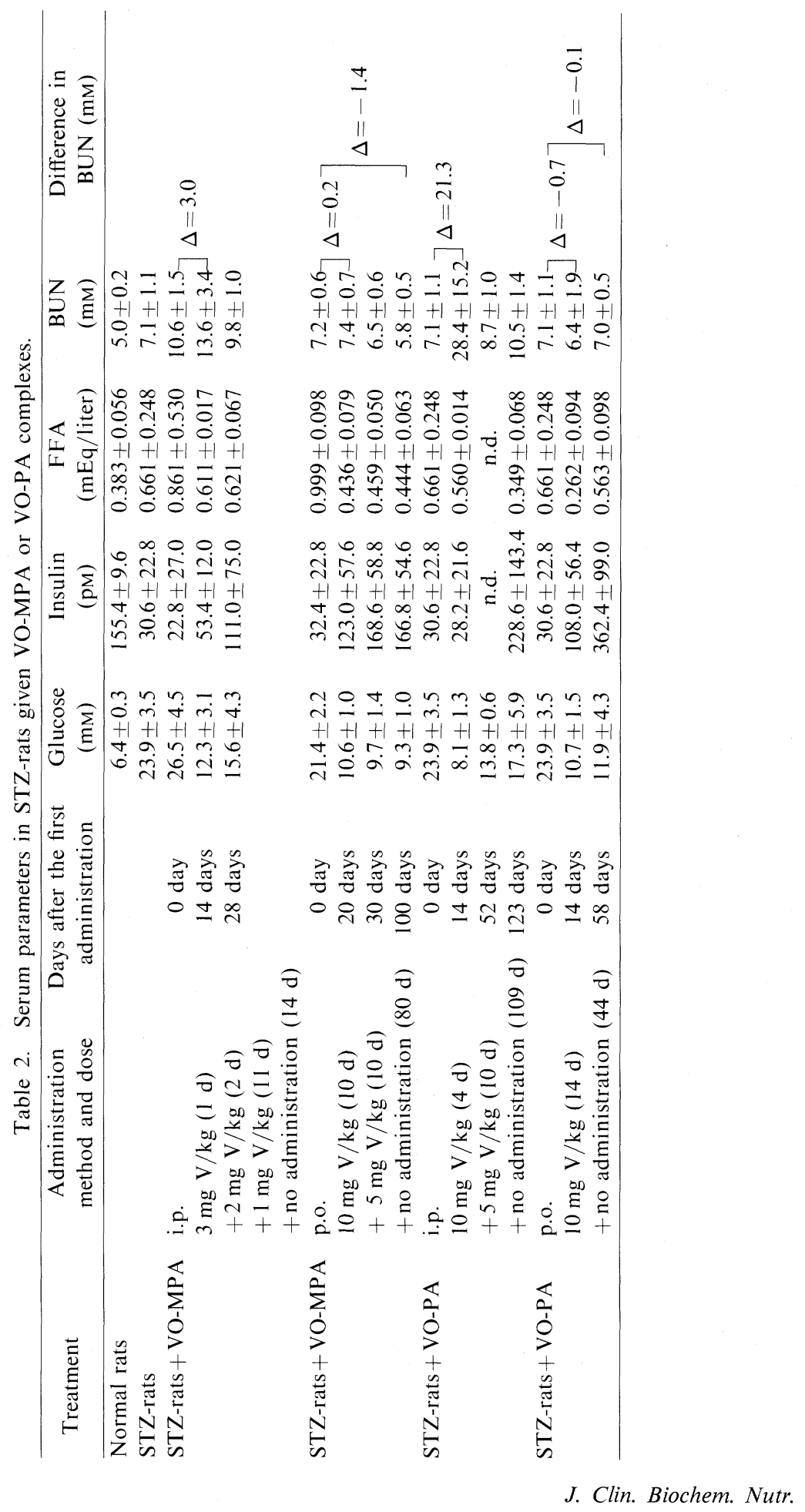


and 100 days appeared to be improved in comparison with the initial BUN levels at day 0 .

\section{Oral glucose tolerance test}

Once the serum glucose levels of STZ-rats treated with VO-MPA had dropped to a normal range, the animals received a glucose tolerance test on the 14th day after the cessation of complex administration. As shown in Fig. 6, the serum glucose levels of untreated STZ-rats increased to a maximum (approx. $28 \mathrm{~mm}$ ) at $1 \mathrm{~h}$ after the glucose administration, and then gradually decreased but still remained high. In contrast, the blood glucose levels of STZ-rats treated with VO-MPA or VO-PA (approx. $12 \mathrm{~mm}$ glucose) did not increase above control level (approx. 11 $\mathrm{mM}$ ). These results indicated that VO-MPA or VO-PA treatment alleviated diabetes in STZ-rats and that there was no difference in the alleviation effect between the two complexes.

\section{Organ distribution of vanadium in STZ-rats given VO-MPA}

Total vanadium distribution in STZ-rats treated with VO-MPA complex was examined by an NAA method, which is the most reliable for vanadium determination among many methods [40]. As shown in the open columns of Figs. 7 and 8, vanadium accumulated in almost all tissues, particularly in bone and kidney, and in the mitochondrial fraction of the liver and in the supernatant of the kidney of STZ-rats receiving VO-MPA by i.p. injections. Similar tendencies were observed in

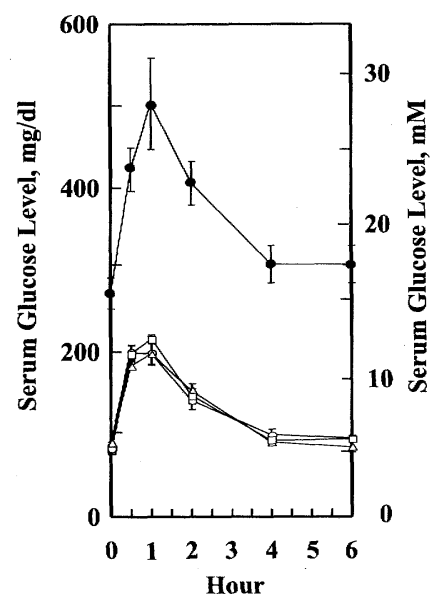

Fig. 6. Glucose tolerance tests for control non-diabetic rats, STZ-induced diabetic rats, and STZ-rats receiving daily oral treatments with VO-PA or VO-MPA complex. Glucose tolerance tests were performed on rats fasted for $12 \mathrm{~h}$ and then given glucose solution ( $40 \%$ in water) orally at a dose of $3 \mathrm{~g} / \mathrm{kg}$ body weight. Symbols are as follows: Control rats (-○-), STZ-rats (-๑), STZ-rats treated with VO-PA $(-\triangle-)$ and STZ-rats treated with VO-MPA $(-\square-)$. Values are the mean \pm SD for 3 rats.

Vol. 23, No. 2, 1997 


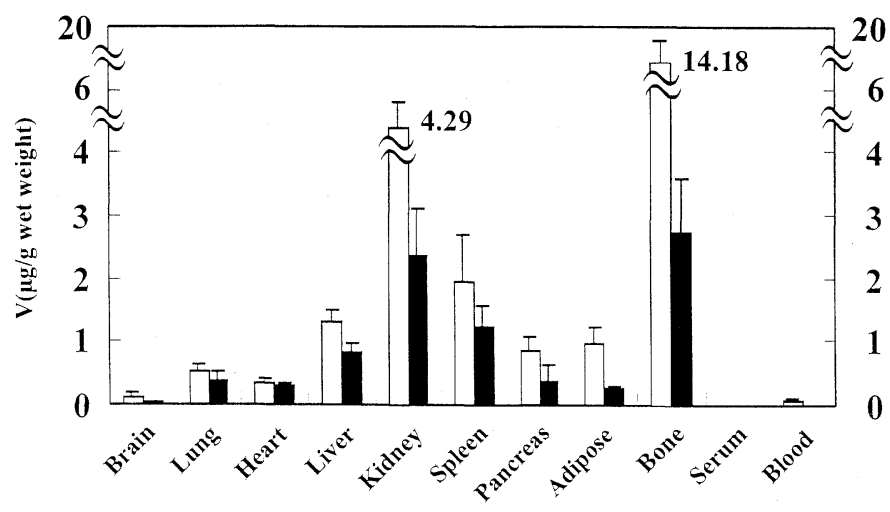

Fig. 7. Organ distribution of total vanadium in STZ-induced diabetic rats receiving daily i.p. or oral treatments of VO-MPA complex. $\square$, i.p. administration, $3 \mathrm{mg}(58.8 \mu \mathrm{mol})$ $\mathrm{V} / \mathrm{kg}$ body weight for the first day and then $2 \mathrm{mg}(39.2 \mu \mathrm{mol}) \mathrm{V} / \mathrm{kg}$ body weight for 2 days and then $1 \mathrm{mg}(19.6 \mu \mathrm{mol}) \mathrm{V} / \mathrm{kg}$ body weight for 11 days, and then no treatment for 7 days. $\mathbf{m}$, Oral administration, $10 \mathrm{mg}(196.0 \mu \mathrm{mol}) \mathrm{V} / \mathrm{kg}$ body weight for the first 10 days and then $5 \mathrm{mg}(98.0 \mu \mathrm{mol}) \mathrm{V} / \mathrm{kg}$ body weight for the following 10 days. Organs of STZ-rats treated with VO-MPA complex were removed and lyophilized. Total vanadium concentrations in them were determined by the NAA method (Kyoto Univ., Nuclear Reactor Institute).

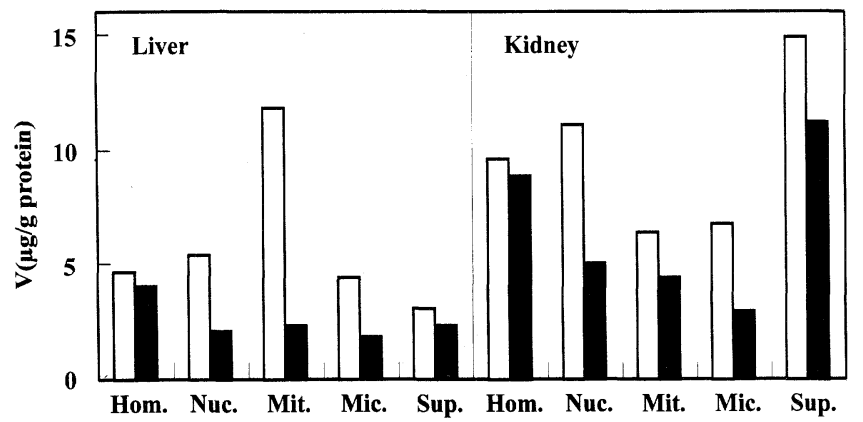

Fig. 8. Subcellular distributions of total vanadium in the liver and kidney of STZ-induced diabetic rats receiving daily i.p. or oral treatments of VO-MPA complex. STZ-rats were given daily VO-MPA complex intraperitoneally ( $\square$ ) or orally $(\boldsymbol{\square})$ at the same administration schedules and doses as described for Fig. 7. Liver and kidney were homogenized and separated into the four subcellular fractions. The fractions were lyophilized. Total vanadium and protein concentrations were determined by the NAA method and the Lowry method, respectively. Hom, whole homogenate; Nuc, nucleus; Mit, mitochondrion; Mic, microsome; Sup, supernatant.

vanadium distribution in STZ-rats given VO-MPA by oral administration except for an accumulation in the mitochondrial fraction of the liver (closed column in Fig. 8). Vanadium accumulation in the bone of rats receiving i.p. injections of VO-MPA was remarkable (approximately 3.3 times that in the kidney and 11 times 
that in the liver). In addition, these results were similar to the distribution of vanadium in rats treated with i.p. injections of VO-PA (Figs. 9 and 10). Accumulation in bone was approximately 4.7 times that in the kidney and 35 times that in the liver.

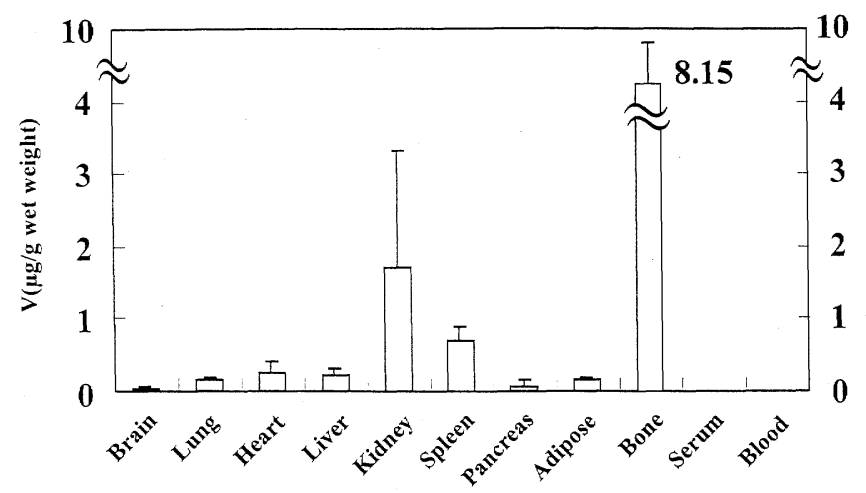

Fig. 9. Organ distribution of total vanadium in STZ-induced diabetic rats receiving daily i.p. administration of VO-PA complex: $10 \mathrm{mg}(196.0 \mu \mathrm{mol}) \mathrm{V} / \mathrm{kg}$ body weight for the first 4 days, $5 \mathrm{mg}(98.0 \mu \mathrm{mol}) \mathrm{V} / \mathrm{kg}$ body weight for 10 days, and then no treatment for 110 days. Organs of STZ-rats treated with VO-PA complex were removed and lyophilized. Total vanadium concentrations in them were determined by the NAA method (Kyoto Univ., Nuclear Reactor Institute).

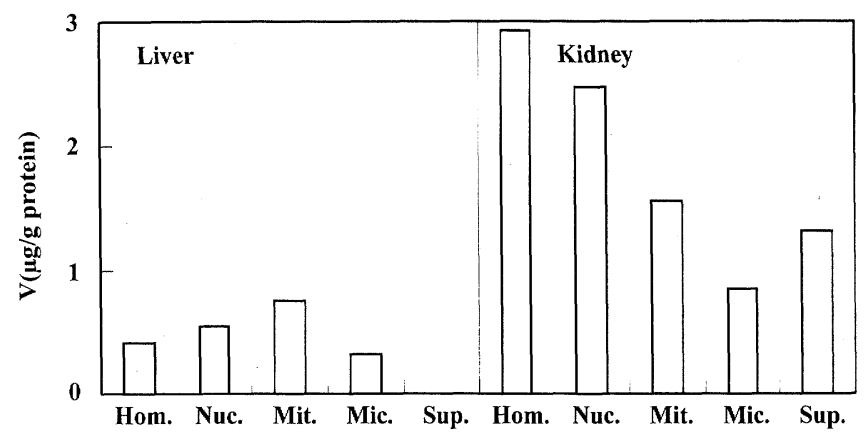

Fig. 10. Subcellular distributions of total vanadium in the liver and kidney of STZinduced diabetic rats receiving daily i.p. administration with VO-PA. STZ-rats were given VO-PA at the same administration schedules and doses as described for Fig. 9. Liver and kidney were homogenized and separated into the four subcellular fractions. The fractions were lyophilized. Total vanadium and protein concentrations were determined by the NAA method and the Lowry method, respectively. Hom, whole homogenate; Nuc, nucleus; Mit, mitochondrion; Mic, microsome; Sup, supernatant.

Vol. 23, No. 2, 1997 


\section{DISCUSSION}

We previously reported that the VO-PA complex was effective by oral administration or by i.p. injection to treat STZ-induced diabetes in rats [26]. Thus, we used the VO-PA complex as a leading compound to develop more active vanadyl complexes than VO-PA by preparing several vanadyl complexes (Fig. 1), and examined the relationships between their structures and insulin-mimetic activity on the basis of the results of in vitro and in vivo experiments.

VO-MPA complex with $\operatorname{VO}\left(\mathrm{N}_{2} \mathrm{O}_{2}\right)$ coordination mode, which has a methyl group on the picolinate structure and thus gives the highest partition coefficient among complexes examined (Table 1), was found to be more effective at $5 \times 10^{-4}$ $M$ to inhibit FFA release from the isolated rat adipocytes than VS (Fig. 2), suggesting its high incorporation into the cells. From these results, we selected the VO-MPA complex and performed in vivo experiments in which the doses of VO-MPA complex were compared with those of VO-PA. When VO-MPA complex was given daily to STZ-rats by i.p. injection at lower doses (total $18 \mathrm{mg} \mathrm{V} / \mathrm{kg}: 3$ $\mathrm{mg} \mathrm{V} / \mathrm{kg}$ for $1 \mathrm{day}+2 \mathrm{mg} \mathrm{V} / \mathrm{kg}$ for 2 days $+1 \mathrm{mg} \mathrm{V} / \mathrm{kg}$ for 11 days) than VO-PA (total $90 \mathrm{mg} \mathrm{V} / \mathrm{kg}: 10 \mathrm{mg} \mathrm{V} / \mathrm{kg}$ for 4 days $+5 \mathrm{mg} \mathrm{V} / \mathrm{kg}$ for 10 days) [26], their serum glucose levels dropped to the normal range immediately after the start of treatment; and the levels remained normal during VO-MPA administration (Fig. 3). When VO-MPA was given to STZ-rats by oral administration (total $150 \mathrm{mg} \mathrm{V} /$ $\mathrm{kg}$ : $10 \mathrm{mg} \mathrm{V} / \mathrm{kg}$ for 10 days $+5 \mathrm{mg} \mathrm{V} / \mathrm{kg}$ for 10 days), their serum glucose levels were also normalized, within 4 or 5 days after the start of treatment; and the levels remained normal during the remainder after administration (Fig. 4). Interestingly, the serum glucose normalization effect continued for 80 days after cessation of oral administration of VO-MPA, indicating that the hypoglycemic period for 80 days by VO-MPA was longer than that for 58 days by VO-PA [26]. These in vivo experimental results suggest that VO-MPA is more effective than VO-PA in terms of having a lower administration dose to give hypoglycemic activity and a longer duration of activity after the administration has been stopped, although the in vitro inhibitory effect of VO-MPA on FFA release from rat adipocytes was almost the same as that of VO-PA. In addition, oral VO-MPA treatment alleviated polyphagia which is characteristic of the diabetic state. Furthermore, body weights of STZ-rats given VO-MPA complex by i.p. injection or oral administration gradually increased during VO-MPA administration. Improvement of diabetes by VOMPA administration was evidenced by the results of the glucose tolerance test (Fig. 6). The blood glucose level of STZ-rats treated with VO-MPA did not increase appreciably and was comparable with those of the control animals and STZ-rats treated with VO-PA, indicating that VO-MPA treatment apparently alleviated diabetes in STZ-rats. Both toxicity of VO-MPA and organ distribution of vanadium were considered to contribute to these important observations such as orally active and long-term acting characteristics of the vanadyl complex to treat 
the diabetic state. Actually, BUN levels, an index of renal toxicity, of STZ-rats given VO-MPA complex orally remained relatively low in comparison with those of animals given the complex by i.p. injections (Table 2). Other serum parameters such as insulin and FFA appeared to be improved by VO-MPA treatments. The long-term action of VO-MPA by oral administration might be related to the accumulation of vanadium, and vanadium was observed mainly in the bone and kidney (Fig. 7). Vanadium accumulated in the bone may be released gradually to other organs via the blood-stream after the cessation of VO-MPA administration, and act to normalize the blood glucose levels for a long period. Further studies on the time-dependent distribution of vanadium in rats treated with vanadyl complexes are necessary to elucidate the action mechanism of vanadium.

In conclusion, we propose an orally active and long-term acting new complex, VO-MPA, which has more potent pharmacological effectiveness to treat IDDM in STZ-rats at a low dose than the VO-PA complex. In addition, no decrease in body weight or increase in BUN level was observed, suggesting the low toxicity of the complex in terms of BUN. These features of VO-MPA might be dependent on its relatively high lipid solubility, which relates to the incorporation of the complex into the cells in the whole body. The VO-MPA complex is thus indicated to be a possible agent to treat IDDM. Our current investigations aim at clarifying the mechanism of VO-MPA action.

This work was supported in part by grants from the Ministry of Education, Science, Sports and Culture of Japan, and was carried out in part under the Visiting Researchers Program of the Research Reactor Institute, Kyoto University.

\section{REFERENCES}

1. Hopkins, L.L., Jr., and Mohr, H.E. (1971): Newer Trace Elements in Nutrition, ed. by Mertz, W., and Cornatzen, W.E., Marcel Dekker, New York, pp. 195-213.

2. Simons, T.J.B. (1979): Vanadate-A new tool for biologists. Nature, 281, 337-338.

3. Nechay, B.R., Nanninga, L.B., Nechay, P.S.E., Post, R.L., Grantham, J.J., Macara, I.G., Kubena, L.F., Phillips, T.D., and Nielsen, F.H. (1986): Role of vanadium in biology. Fed. Proc., 45, 123-132.

4. Cantley, L.G., Jr., Josephson, L., Warner, R., Yanagisawa, M., Lechene, C., and Guidotti, G. (1977): Vanadate is a potent (Na-K)-ATPase inhibitor found in ATP derived from muscle. J. Biol. Chem., 252, 7421-7423.

5. Nechay, B.R. (1984): Mechanisms of action of vanadium. Annu. Rev. Pharmacol. Toxicol, 24, 501-524.

6. Heylinger, C.E., Tahiliani, A.G., and McNeill, J.H. (1985): Effect of vanadate on elevated blood glucose and depressed cardiac performance of diabetic rats. Science, 227, 1474-1477.

7. Liu, H., and McNeill, J.H. (1994): Effect of vanadium treatment on the alterations of cardiac glycogen phosphorylase and phosphorylase kinase in streptozotocin-induced chronic diabetic rats. Can. J. Physiol. Pharmacol., 2, 1537-1543.

8. Candura, S.M., Manzo, L., Marraccini, P., Coccini, T., and Tonini, M. (1994): Investigation into vanadate-induced potentiation of smooth muscle contractility in the rabbit isolated ileum. Life Sci., 54, 237-244.

9. Oeztuerk, Y., Yildizoglu-Ari, N., Pekiner, C., Oezcelikay, A.T., and Altan, V.M. (1994): Vanadate treatment reverses gastrointestinal complications in the streptozotocin-diabetic

Vol. 23, No. 2, 1997 
rats. Gen. Pharmacol., 25, 1109-1114.

10. Adachi, K., Endo, M., Nagata, M., and Tamai, A. (1995): Effects of vanadate on glucose metabolism in the lens of rats with streptozotocin-induced diabetes. Ketohexokinase and aldolase activities. Yonago Acta Med., 38, 117-124.

11. Cordera, R., Andraghetti, G., DeFronzo, R.A., and Rossetti, L. (1990): Effect of in vivo vanadate treatment on insulin receptor tyrosine kinase activity in partially pancreatectomized diabetic animals. Endocrinology, 126, 2177-2183.

12. Fantus, I.G., Kadota, S., Deragon, G., Foster, B., and Posner, B. (1989): Pervanadate [peroxide(s) of vanadate] mimics insulin action in rat adipocytes via activation of the insulin receptor tyrosine kinase. Biochemistry, 28, 8864-8871.

13. Green, A. (1986): The insulin-like effect of sodium vanadate on adipocyte glucose transport is mediated at a post insulin-receptor level. Biochem. J., 238, 663-669.

14. Dubyak, G.R., and Kleinzeller, A. (1980): The insulin-mimetic effects of vanadate in isolated rat adipocytes. Dissociation from effects of vanadate as a $\left(\mathrm{Na}^{+}-\mathrm{K}^{+}\right)$-ATPase inhibitor. J. Biol. Chem., 255, 5306-5312.

15. Schechter, Y., and Karlish, S.J.D. (1980): Insulin-like stimulation of glucose oxidation in rat adipocytes by vanadyl (VI) ions. Nature, 284, 556-558.

16. Duckworth, W.C., Solomon, S., Liepnieks, J., Hamel, F.G., Hand, S., and Peavy, D.E. (1988): Insulin-like effects of vanadate in isolated rat adipocytes. Endocrinology, 122, 22852289.

17. Tamura, S., Brown, T.A., Dubler, R.E., and Larner, J. (1984): Insulin-like effect of vanadate on adipocyte glycogen synthase and on phosphorylation of 95,000 dalton subunit of insulin receptor. Biochem. Biophys. Res. Commun., 113, 80-86.

18. Brichard, S.M., and Henquin, J.C. (1995): The role of vanadium in the management of diabetes. Trends Pharmacol. Sci., 16, 265-270.

19. Shechter, Y. (1990): Insulin-mimetic effects of vanadate. Diabetes, 39, 1-5.

20. Meyerovitch, J., Farfel, Z., Sock, J., and Shechter, Y. (1987): Oral administration of vanadate normalizes blood glucose levels in streptozotocin-treated rats. J. Biol. Chem., 262, 6658-6662.

21. Ramanadham, S., Mongold, J.J., Brownsey, R.W., Cros, G.H., and McNeill, J.H. (1989): Oral vanadyl sulfate in the treatment of diabetes mellitus in the rat. Am. J. Physiol., 257, B904-H911.

22. Sakurai, H., Tsuchiya, K., Nukatsuka, M., Sofue, M., and Kawada, J. (1990): Insulin-like effect of vanadyl ion on streptozotocin-induced diabetic rats. J. Endocrinol., 126, 451-459.

23. Sakurai, H., Tsuchiya, K., Nukatsuka, M., Kawada, J., Ishikawa, S., Yoshida, H., and Komatsu, M. (1990): Insulin-mimetic action of vanadyl complexes. J. Clin. Biochem. Nutr., 8, 193-200.

24. McNeill, J.H., Yuen, V.G., Hoveyda, H.R., and Orvig, C. (1992): Bis(maltolato)-oxovanadium (IV) is a potent insulin mimic. J. Med. Chem., 35, 1489-1491.

25. Watanabe, H., Nakai, M., Komazawa, K., and Sakurai, H. (1994): A new orally active insulin-mimetic vanadyl complex: Bis(pyrrolidine-N-carbodithioato)oxovanadium (IV). $J$. Med. Chem., 37, 876-877.

26. Sakurai, H., Fujii, K., Watanabe, H., and Tamura, H. (1995): Orally active and long-term acting insulin-mimetic vanadyl complex: Bis(picolinato)oxovanadium (IV). Biochem. Biophys. Res. Commun., 214, 1095-1101.

27. Tamura, S., Brown, T.A., Whipple, J.H., Fujita-Yamaguchi, Y., Dubler, R.E., Cheng, K., and Larner, J. (1984): A novel mechanism for the insulin-like effect of vanadate on glycogen synthase in rat adipocytes. J. Biol. Chem., 259, 6650-6658.

28. Nakai, M., Watanabe, H., Fujiwara, C., Kakegawa, H., Satoh, T., Takada, J., Matsushita, R., and Sakurai, H. (1995): Mechanism on insulin-like action of vanadyl sulfate: Studies on interaction between rat adipocytes and vanadium compounds. Biol. Pharm. Bull., 18, 719725 .

29. Schwabe, U., Puchstein, C., Hannemann, H., and Sochtig, E. (1979): Activation of adenylate 
cyclase by vanadate. Nature, 277, 143-145.

30. Huckle, W.H., and Earp, H.S. (1994): Synergistic activation of tyrosine phosphorylation by $o$-vanadate plus calcium ionophore A23187 or aromatic 1,2-diols. Biochemistry, 33, 15181525 .

31. Elberg, G., Li, J., and Shechter, Y. (1994): Vanadium activates or inhibits receptor and non-receptor protein tyrosine kinases in cell-free experiments, depending on its oxidation state. J. Biol. Chem., 269, 9521-9527.

32. Ueki, H., Yamasaki, Y., Higo, K., Motoyashiki, T., Kawabata, H., and Morita, T. (1995): Regulation of cyclic AMP phosphodiesterase activity by particulate protein tyrosine kinase and phosphotyrosine phosphatase activities sensitive to sodium orthovanadate. Biol. Pharm. Bull., 18, 214-218.

33. Morita, T., Imagawa, T., Kanagawa, A., and Ueki, H. (1995): Sodium orthovanadate increases phospholipase $\mathrm{A}_{2}$ activity in isolated rat fat pads: A role of phospholipase $\mathrm{A}_{2}$ in the vanadate-stimulated release of lipoprotein lipase activity. Biol. Pharm. Bull., 18, 347349.

34. Aktan, F., and Nebioglu, S. (1994): Effect of vanadium compounds on calmodulin activity in experimental diabetes in rats. Can. J. Physiol. Pharmacol., 72, 753-758.

35. Strout, H.V., Vicario, P.P., Saperstein, R., and Slater, E.E. (1989): The insulin-mimetic effect of vanadate is not correlated with insulin receptor tyrosine kinase activity nor phosphorylation in mouse diaphragm in vivo. Endocrinology, 124, 1918-1924.

36. Hogeboom, G. (1955): Fractionation of cell components of animal tissues. Methods Enzymol., 1, 16-19.

37. Lowry, O.H., Rosebrough, N.J., Farr, A.L., and Randall, R.J. (1951): Protein measurement with the folin phenol reagent. J. Biol. Chem., 193, 265-275.

38. Fantus, I.G., Ahmad, F., and Deragon, G. (1990): Vanadate augments insulin binding and prolongs insulin action in rat adipocytes. Endocrinology, 127, 2716-2725.

39. Shechter, Y., Shisheva, A., Lazar, R., Libman, J., and Shanzer, A. (1992): Hydrophobic carriers of vanadyl ions augment the insulinomimetic actions of vanadyl ions in rat adipocytes. Biochemistry, 31, 2063-2068.

40. Heydorn, K. (1983): Metal Ions in Biological Systems, Vol. 16, ed. by Sigel, H., Marcel Dekker, New York, pp. 123-138. 